\title{
Original
}

\section{Morphological Changes of the Vestibular Labyrinth by Experimental Perilymph Fistula}

\author{
Naohito Kukita and Yasuya Nomura
}

\begin{abstract}
The vestibular pathology of a perilymph fistula produced either by injecting an artificial perilymph into the subarachnoid space or by suctioning the perilymph through the round window was studied in animal models. Vestibular changes observed were the collapse of the otolithic organs or the semicircular ducts, which were demonstrated by computer graphics from serially sectioned specimens. Collapse of the utricular wall was common. In some animals, part of the utricular wall collapsed onto the otolithic membrane of the parts interna. When changes were severe, the whole macula utriculi was covered by the collapsed wall. The trabecular mesh was torn in the utricle and semicircular canals. Collapse was irreversible. However, no otolithic membrane, sensory epithelium or nerve fibers were involved. Collapse of the ampullary wall, saccule and cochlea were also evident. The mechanism of the collapse is explained by the finding of the rupture of the Reissner's membrane. Withdrawal of the endolymph from the cochlea possibly caused the collapse of the vestibular membranous labyrinth. The sensory cells of the macula utriculi being stimulated by the collapsed utricular wall onto the otolithic membrane could explain the persistent dizziness of patients with preilymph fistula.
\end{abstract}

Key words: perilymph fistula, animal model, collapsed membranous labyrinth, computer graphics, vestibular symptoms

\section{Introduction}

Perilymph fistula is an inner ear problem with symptoms of tinnitus, hearing loss, dizziness and disequilibrium. Leakage of the perilymph occurs from the oval and/or round window, even in relation to physical actions in daily life. However, the pathophysiology of the disease is unknown, because of the scarcity of histopathological study of the human temporal bone. The purpose of the present study was to examine vestibular changes in animal models of perilymph fistula.

\section{Materials and Methods}

Healthy albino guinea pigs were used in this series of experiments. Two animal models were produced by: 1) injection method, and 2) suction method.

The injection method is based on Gocdhil!'s explosive route theory ${ }^{11}$. Artificial perilymph was injected into the subarachnoid space until the oval and/or round window ruptured ${ }^{2}$. With the alternative suction method, $4 \mu \mathrm{l}$ of perilymph was suctioned through the round Department of Otolaryngology, Showa University School of Medicine, 1-5-8 Hatanodai, Shinagawa-ku, Tokyo 142, Japan. 
window membrane ${ }^{3)}$.

Animals were sacrificed immediately or 3 to 8 weeks after creation of a perilymph fistula under deep anesthesia induced by injecting a large dose of Nembutal. Serial sections were made after embedding in celloidin. Histopathological findings in these animal models were identical $^{3)}$. Serial celloidin specimens of 4 injection and 3 suction animals were used in this study. Collapse of the utricular wall was common in these animals, and this may explain some of the symptoms of vestibular disorder in patients with perilymph fistula.

To clarify the relation between the collapse of the utricular wall and the otolithic membrane, drawings of morphological changes were fed to a computer and a graphic reconstruction was made using the Cosmozone 2SB (Nikon Co. Ltd. Tokyo, Japan).

Three animals were sacrificed after suctioning $4 \mu \mathrm{l}$ of perilymph from the left inner ear. The membranous labyrinth of the pars superior was dissected out after Sudan Black B staining. The aim was to provide direct observation of the unsectioned membranous labyrinth. The right inner ear served as a control. Observation was made under a stereomicroscope (SV8, Carl Zeiss Co. Ltd. Germany).

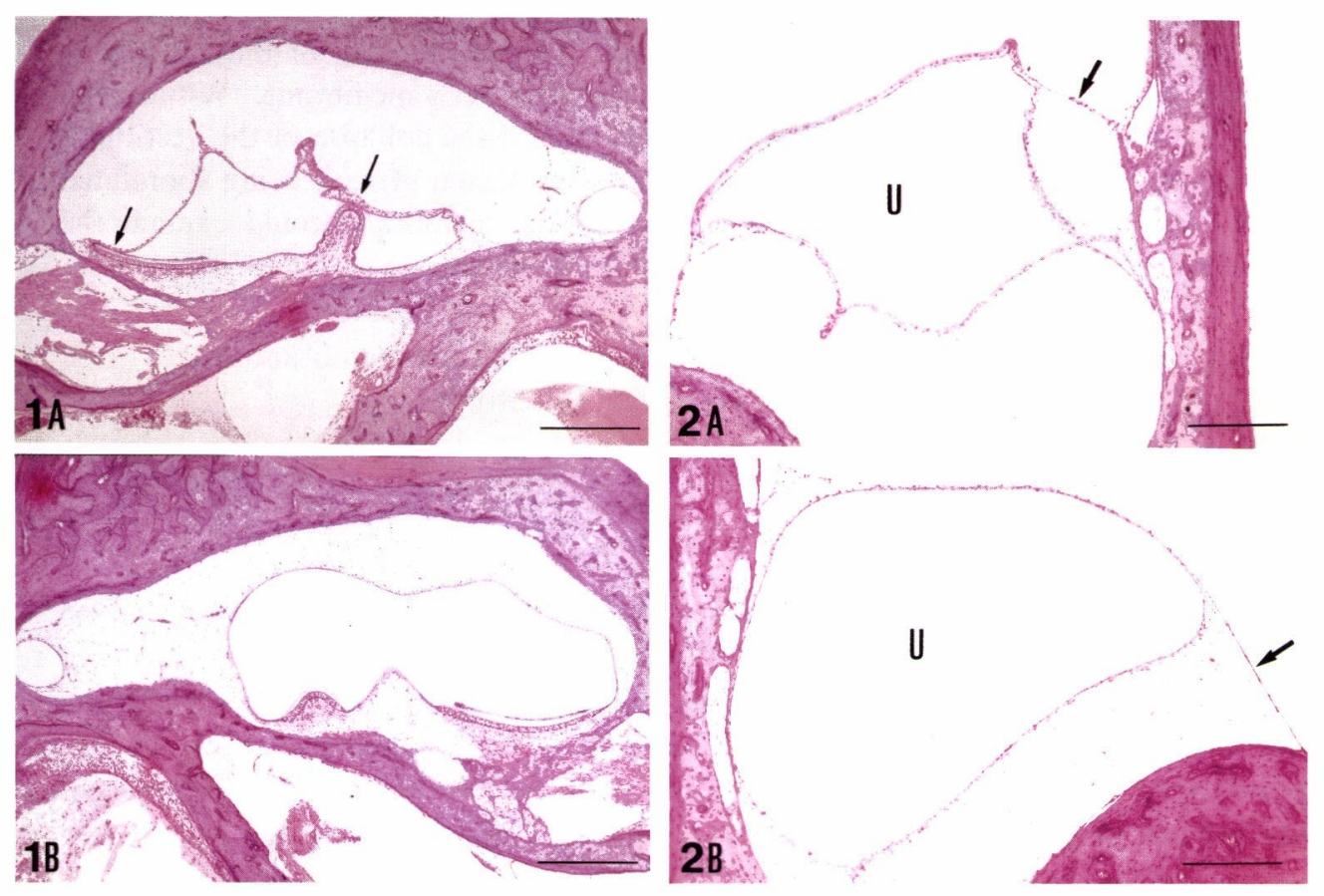

Fig. 1A. Collapse of the utricular and ampullary wall (arrows). Four weeks after artificial perilymph injection. (scale: $0.5 \mathrm{~mm}$ )

Fig. 1B. Control. Normal contour of the utricular and ampullary wall with the trabecular mesh around it. (scale: $0.5 \mathrm{~mm}$ )

Fig. 2A. The utricle shows collapse, while the membrana limitans is intact. Three weeks after perilymph suction. (scale: $0.2 \mathrm{~mm}$ )

Fig. 2B. Normal side. (scale: $0.2 \mathrm{~mm}$ ) $\mathrm{U}$ : utricle, arrow: membrana limitans. 


\section{Results}

Pathological changes observed in the pars superior consisted of tearing of the trabecular mesh, and collapse of the utricular wall and semicircular ducts. There was no hydrops nor rupture of the membranous labyrinth of the pars superior.

The utricle

Seven animals showing collapse of the utricular wall were selected for this study. All showed nearly complete loss of the trabecular mesh around the utricle (Fig. 1). The membrana limitans, however, was intact in all cases (Fig. 2). Collapse of the utricular wall was observed in the medial part of the utricle, which appeared to be a site of predilection. The more severer the collapse, the wider the area of the macula utriculi that was covered by the collapsed wall from the medial part laterally.

Collapse of the utricular wall is classified as grade 1, 2, or 3 (Fig. 3). In grade 1 collapse, the utricular wall covers a small part of the pars interna of the macula utriculi. Three animals belonged to this group: 2 injection animals sacrificed at 4 weeks and 8 weeks, and 1 suction animal sacrificed immediately after production of the fistula. The utricular wall covers half of the macula utriculi in grade 2 collapse. Three animals belonged to this group: 2 injection animals sacrificed immediately and after 6 weeks, and 1 suction animal sacrificed immediately after production of the fistula. The utricular wall covers the total macula utriculi in grade 3 collapse. One suction animal sacrificed 3 weeks after production of the fistula showed such a change.

The sensory cells of the macula utriculi were present in all animals. There was a strand connecting the bony wall and the collapsed utricular wall in 5 of 7 animals: 3 , grade $1 ; 1$, grade 2; and 1, grade 3 (Fig. 4).

Computer graphics of two specimens revealed collapse of the utricular wall and ampulla of the semicircular canal (Figs. 5, 6). It also showed that the collapsed wall was in contact with the pars interna of the otolithic membrane.

Dissection of the pars superior of the suctioned animals failed to show collapse of the utricular wall. However, the ampullary wall of the anterior and lateral canals show a collapse in 2 of 3 animals.

\section{Semicircular canals}

The ampullae of the semicircular canals showed collapse of their roofs. The collapsed ampullary walls fell down on the crista or leaned against the crista with or without the cupula (Fig. 7). Dissected specimens demonstrated collapse at the top of the ampullary wall

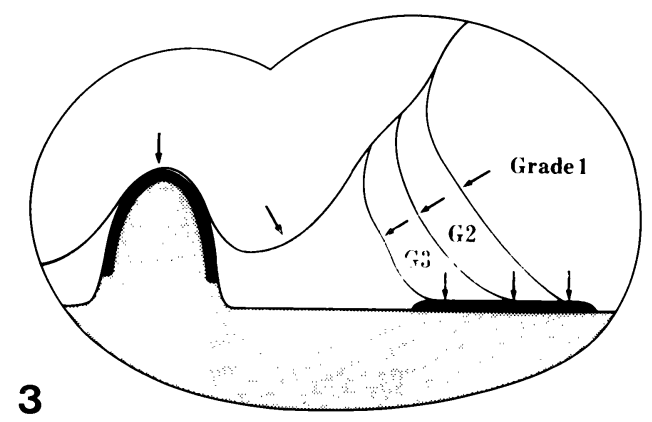

Fig. 3. Schema showing degrees of collapse. For explanation, see text. 

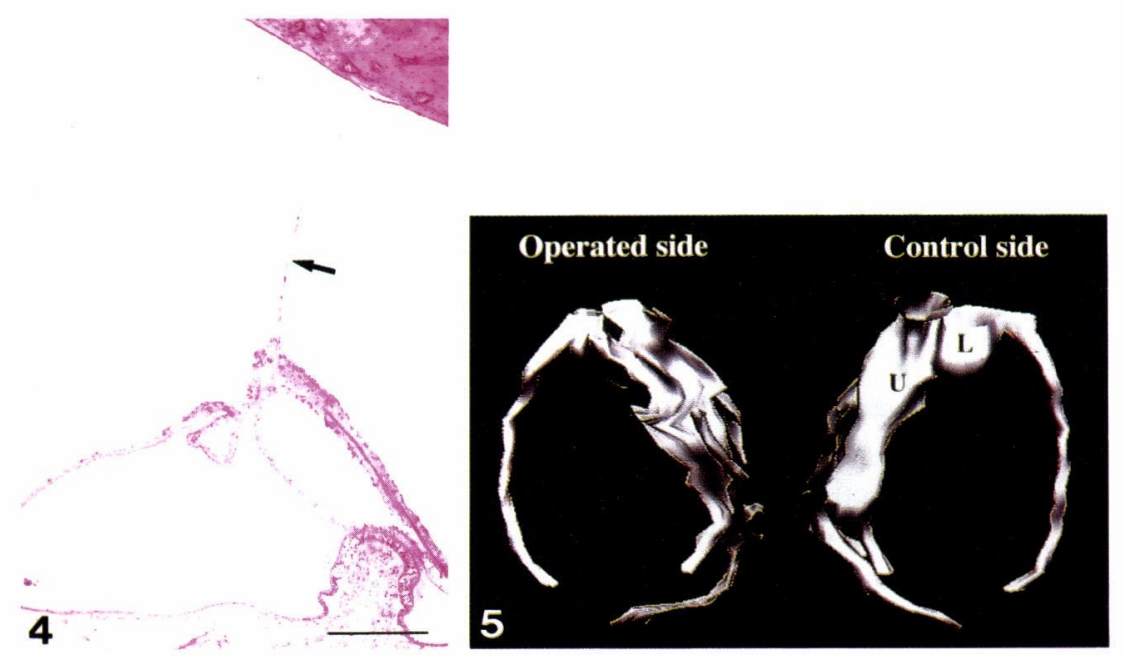

Fig. 4. A strand connecting the bony wall and collapsed utricular wall (arrow). Three weeks after suctioning perilymph. (scale: $0.2 \mathrm{~mm}$ )

Fig. 5. Graphic reconstruction of the collapsed pars superior. Four weeks after artificial perilymph injection.

$\mathrm{U}$ : utricle, L: lateral ampulla.
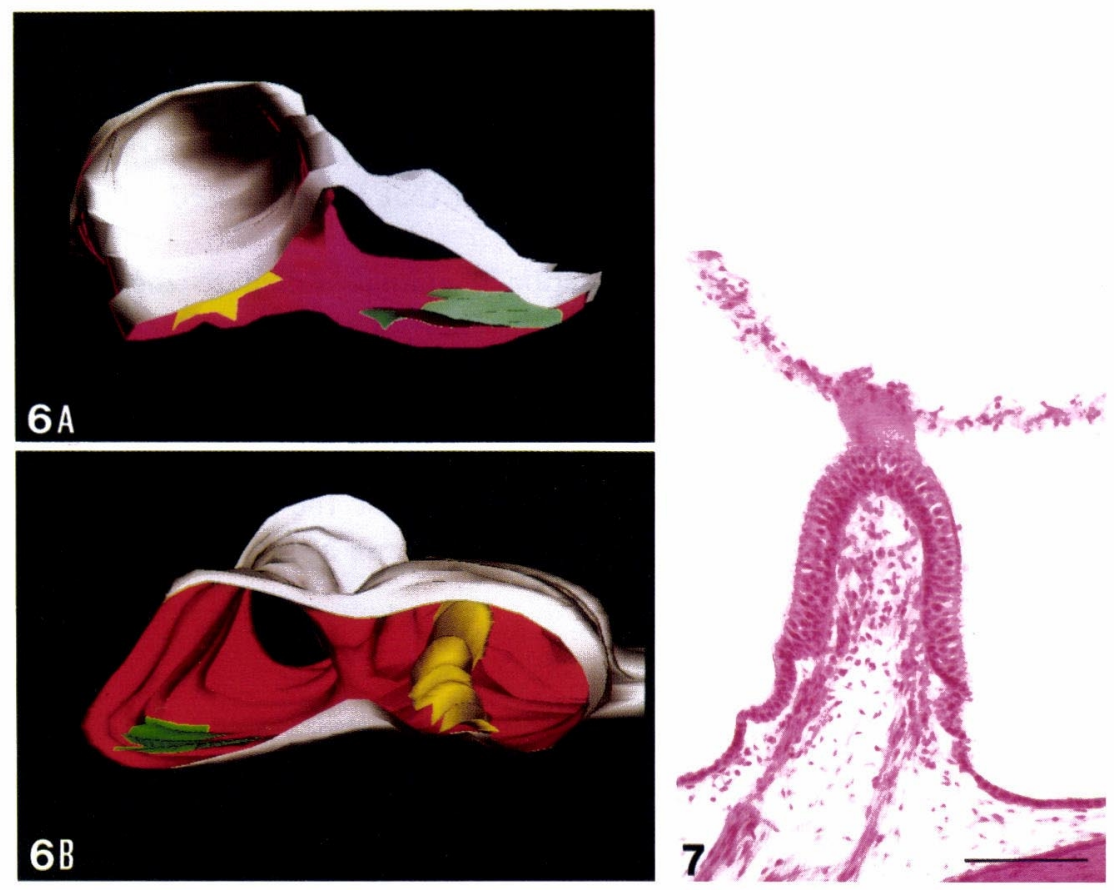

6B

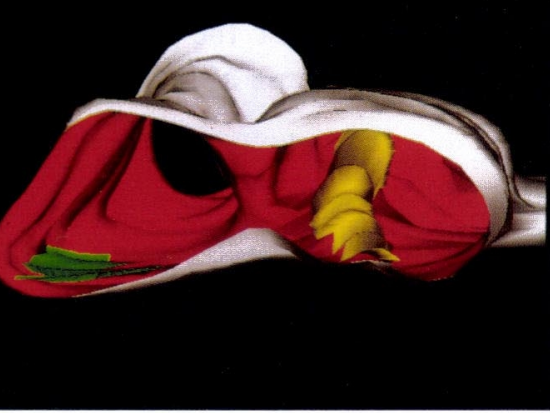

Fig. 6. Graphic reconstruction of the collapsed utricular wall (A). Eight weeks after artificial perilymph injection.

B: Control, Red: inner wall of membranous labyrinth, Green: macula utriculi, Yellow: crista ampullaris of lateral semicircular canal.

Fig. 7. Collapsed ampullary wall fallen down onto the cupula. Eight weeks after artificial perilymph injection. (scale: $0.1 \mathrm{~mm}$ ) 


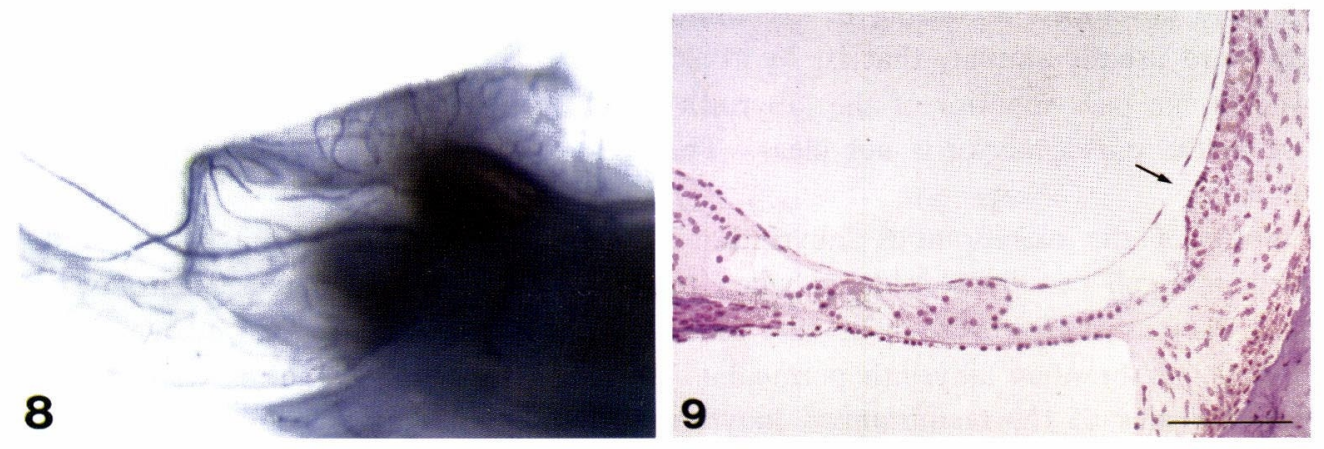

Fig. 8. Collapsed ampullary wall. Dissected specimen immediately after suctioning perilymph.

Fig. 9. Collapsed Reissner's membrane showing a defect (arrow). Four weeks after artificial perilymph injection. (scale: $0.1 \mathrm{~mm}$ )

Table 1. Histopathological changes in membranous labyrinth.

\begin{tabular}{rccccc}
\hline $\begin{array}{c}\text { Animal } \\
\text { No. }\end{array}$ & Method & $\begin{array}{c}\text { Survival } \\
\text { (wks) }\end{array}$ & SCDs & $\begin{array}{c}\text { Classification of } \\
\text { utricular wall collapse }\end{array}$ & $\begin{array}{c}\text { Reissner's } \\
\text { membrane }\end{array}$ \\
\hline 102 & I & 0 & col & G2 & col, rup \\
205 & I & 4 & col & G1 & col, rup \\
210 & I & 6 & col & G2 & col, rup \\
400 & I & 8 & col & G1 & hydrops \\
20 & S & 0 & col & G2 & col, rup \\
403 & S & 0 & col & G1 & col, rup \\
\hline
\end{tabular}

I: injection method, S: suction method, SCDs: semicircular ducts, col: collapsed, rup: ruptured, G1, 2, 3: Grade 1, 2, 3 see text.

(Fig. 8).

Relation between the utricle, semicircular canals, saccule and cochlea

Collapse of the ampullary wall of the three semicircular canals was observed in 3 of 4 injection animals and all of 3 suction animals. Collapse of the saccular wall was observed in these 6 animals. Reissner's membrane was ruptured in 6 (Fig. 9). The temporal bone of one injection animal showed mild collapse of the utricular wall and collapse of the lateral ampulla. The saccule showed collapse and the cochlea showed hydrops.

Histopathological changes are summarized in Table 1.

\section{Discussion}

Perilymph fistula is a common inner ear disorder. However, it is quite often misdiagnosed as Meniere's disease, sudden deafness or other inner ear disorders. Hitherto, no histopathological study of the human temporal bone has been reported in relation to perilymph fistula.

Mere leakage of the perilymph does not produce clinical symptoms. It is possible that pathological changes inside the inner ear are responsible for the symptoms.

Goodhill proposed the theory of explosive and implosive routes in regard to the mechanism leading to leakage of perilymph through the oval and/or round window ${ }^{1)}$. Two animal 
models were developed according to Goodhill's explosive route theory. Their morphologic changes were usually similar, that is, hydrops, rupture and collapse, but only collapse was observed in the pars superior of the labyrinth ${ }^{3)}$. The mechanism of membranous labyrinth collapse in the pars superior is not clear. There are several possible explanations for this phenomena.

1. Rupture of the membranous labyrinth. Escape of endolymph through the ruptured vestibular wall can be considered when pressure of perilymph increase is followed by rapid decrease. However, in serially sectioned specimens there was no evidence of this.

2. Altered membranous labyrinth permeability. Sudden pressure change may alter biological characteristics of the membranous labyrinth. Massive flow of endolymph may occur through the membranous labyrinth to the perilymphatic space.

3. Movement of endolymph in the pars superior to the pars inferior. Endolymph within the pars superior is maintained by the competent utriculoendolymphatic valve. Pressure of perilymph and endolymph increases simultaneously before perilymph leaks into the middle ear. This opens the space adjacent to the valve resulting in endolymph escape from the pars superior into the pars inferior. If there is a rupture in the membranous labyrinth of the pars inferior, this theory is probably true. Rupture of Reissner's membrane was observed in 6 of 7 animals.

When the utricle collapses without rupture of the utricular wall, perilymph may move from the pars inferior to the pars superior through the membrana limitans. Tearing of the trabecular mesh with preservation of the membrana limitans can not easily explain fluid movement between the pars inferior and pars superior.

Collapse of the vestibular labyrinth in the human temporal bone was reported by Marchant and Schuknecht in $1988^{4)}$. They coined the term "vestibular atelectasis" for this condition. Patients with vestibular atelectasis are persistently dizzy. According to Marchant and Schuknecht, several diseases need to be differentiated from vestibular atelectasis. These include Meniere's disease, perilymph fistula, cerebellar infarct, acute vestibular neuritis and multiple sclerosis. It is possible that some cases of vestibular atelectasis reported were patients with perilymph fistula.

A variety of symptoms are observed in patients with perilymph fistula. These can be explained by animal models, in which the histopathology of the temporal bones reveals collapse, hydrops and rupture of the membranous labyrinth ${ }^{1,2)}$. The collapsed utricular wall may sway and stimulate the hair cells beneath when the perilymph moves. This condition is termed "floating labyrinth" or "irritable labyrinth" ${ }_{5,6)}$. The dizziness associated with perilymph fistula subsides after surgical closure of the fistula. Closure of the fistula stops the leakage and movement of perilymph, so stimulation of the hair cells and the consequent symptoms subside. Labyrinthectomy may be considered in patients with persistent dizziness after closure of the fistula.

\section{References}

1) Goodhill V: Sudden deafness and round window rupture. Laryngoscope, 81: 1462-1474 (1971)

2) Nomura $Y$ and Hara M: Experimental perilymphatic fistula. Am J Otolaryngol, 7: 267-275 (1986)

3) Hara M, Nomura $\mathrm{Y}$ and Saito K: Histopathological study of the perilymph suctioned labyrinth. Ann Otol Rhinol Laryngol, 99: 316-320 (1990)

4) Marchant SN and Schuknecht HF: Vestibular atelectasis. Ann Otol Rhinol Laryngol, 97: 565-576 (1988) 
5) Nomura Y, Hara M, Young Y-H and Okuno T: Inner ear morphology of experimental perilymphatic fistula. Am J Otol, 13: 32-37 (1992)

6) Nomura Y, Okuno T, Hara $M$ and Young $Y-H$ : "Floating labyrinth"-Pathophysiology and treatment of perilymph fistula. Acta Otolaryngol, 112: 186-191 (1992)

[Received January 25, 1994: Accepted February 10, 1994] 